\title{
Prevalence of Valvular and Non-valvular Atrial Fibrillation and the Application of Antithrombotic Treatment in a Tertiary Care Hospital
}

\author{
Sahadeb Prasad Dhungana, ${ }^{1}$ Rinku Ghimire ${ }^{2}$ \\ 'Cardiology Unit, Department of Internal Medicine, Nobel Medical College Teaching Hospital, Biratagar, Nepal, \\ ${ }^{2}$ Department of Pharmacology, Nobel Medical College Teaching Hospital, Biratagar, Nepal.
}

\section{ABSTRACT}

Introduction: Atrial fibrillation is a common atrial tachyarrhythmia with an increased risk of thromboembolism. This study aims to provide information about the application of antithrombotic treatment based on risk stratification schemes for stroke in real-life clinical practices.

Methods: This was a descriptive cross-sectional study in 260 patients admitted at the tertiary care hospital with a diagnosis of atrial fibrillation from January 2019 to February 2020 after approval from the Institutional Review Committee (ref. no. 207/2018). Convenient sampling was used. Predisposing conditions for atrial fibrillation, risk factors for stroke, and the use of antithrombotics were obtained based on the pre-structured questionnaires. Data were analyzed by Statistical Package for the Social Sciences version 20.

Results: The prevalence of valvular and non-valvular atrial fibrillation was 125 (48.0\%), and 135 (51.9\%) respectively. Among patients with a non-valvular variant, 102 (75.5\%) had a $\mathrm{CHA}_{2} \mathrm{DS}_{2}$ VAScscore of $\geq 2$ who were eligible for oral anticoagulants, $13(9.6 \%)$ patients received it with a majority having sub-therapeutic international normalized ratio. Among patients with valvular type, only 47 $(37.6 \%)$ patients were receiving oral anticoagulants and $20(42.5 \%)$ patients achieved therapeutic international normalized ratio. Two hundred forty three $(93.4 \%)$ patients had dilated left atrium ( $\geq 40 \mathrm{~mm}), 119$ (45.9\%) had hypertension and 27 (10.3\%) had diabetes mellitus.

Conclusions: Antithrombotics were markedly underused in patients with atrial fibrillation. There is a need for proper application of risk stratification schemes for stroke and appropriate use of antithrombotics to prevent thromboembolism.

Keywords: anticoagulants; atrial fibrillation; risk assessment; stroke.

\section{INTRODUCTION}

\begin{abstract}
Atrial fibrillation (AF) is the most common sustained tachyarrhythmia which affects $1-2 \%$ of the general population. ${ }^{1} \mathrm{AF}$ is a risk factor for stroke and thromboembolism. There is higher mortality and morbidity when a stroke occurs in association with AF. Therefore, stroke prevention is a major concern when managing patients with AF. Various clinical risk factors have been identified, which confer a high risk of stroke.
\end{abstract}

An important aspect of AF management is the prevention of stroke, using antithrombotic agents including anti-platelets and oral anticoagulants (OACs). ${ }^{2}$ Although the literature provides simplified rules for the use of antithrombotic in patients with AF, studies have shown that OAC is frequently underused in AF patients with reported use in between 30 and $60 \% .{ }^{1,3,4}$

This suboptimal use may be related to various physician and patient factors. This study provides information

Correspondence: Dr. Sahadeb Prasad Dhungana, Department of Internal Medicine, Cardiology Unit, Nobel Medical College Teaching Hospital, Biratnagar, Nepal. Email: drsadhu@ gmail.com, Phone: +977-9861773031. 
Dhungana et al. Prevalence of Valvular and Non-valvular Atrial Fibrillation and the Application of Antithrombotic Treatment...

about the application of antithrombotic treatment for patients with valvular atrial fibrillation (VAF) and non-valvular atrial fibrillation (NAVF) in a tertiary care hospital.

\section{METHODS}

This descriptive cross-sectional study was conducted from January 2019 to February 2020. A total of 260 patients with AF (age $\geq 15$ years) who attended the cardiology clinic or admitted to the cardiology unit of Nobel Medical College Teaching Hospital were enrolled based on a convenient sampling method. Ethical approval was obtained from the institutional review committee (NMCTH ref. no. 207/2018) before starting the study. The sample size $(n)$ was calculated using the formula,

$\mathrm{n}=\mathrm{Z}^{2} \times \mathrm{p} \times(1-\mathrm{p}) / \mathrm{e}^{2}$

$=(1.96)^{2} \times 0.138 \times 0.86 /(0.05)^{2}$

$=185$

Where,

$\mathrm{n}=$ sample size

$Z=1.96$ at $95 \%$ Confidence Interval $(\mathrm{Cl})$

$p=$ prevalence of $A F, 13.8 \%^{6}$

$\mathrm{e}=$ margin of error, $5 \%$

Taking a $10 \%$ non-respondent rate, the sample size becomes 204. However, the total sample size was 260 .

All participants were asked relevant questions to note demographic information, co-morbid conditions, use of antithrombotic agents, and risk factors for stroke based on pre-structured questionnaires. The international normalized ratio (INR) value of patients who were on vitamin $\mathrm{K}$ antagonists (VKA) was noted at the time of enrollment. $\mathrm{CHA}_{2} \mathrm{DS}_{2}-\mathrm{VASc}$ (Congestive heart failure, Hypertension, Age $\geq 75$ years, Diabetes mellitus, prior stroke or transient ischemic attack, vascular disease, age $65-74$, female sex) score was determined by using age and co-morbidities at the time of enrollment for stratifying stroke risk. ${ }^{5}$ Electrocardiogram (ECG) and echocardiogram (Echo) were performed in each case.

Data were entered in Microsoft excel 2007 and converted into IBM Statistical Package for the Social Sciences (SPSS), version 20. Continuous and categorical variables were presented as mean, percentage, and range. The tabular presentation was made for necessary variables.

\section{RESULTS}

The prevalence of valvular AF is 125 (48.0\%) and non-valvular AF is $135(51.9 \%)$. The majority of patients $156(60 \%)$ were of age $>60$ years. The mean heart rate was 95.65 beats per minute. Left atrial/ left atrial appendage clot was seen in 30 (11.53\%) patients (Table 1).

\begin{tabular}{|c|c|}
\hline \multicolumn{2}{|c|}{$\begin{array}{l}\text { Table 1. Baseline characteristics of patients with } \\
\text { atrial fibrillation }(n=260) \text {. }\end{array}$} \\
\hline Characteristics & Frequency $\mathrm{n}(\%)$ \\
\hline Non-valvular AF & $135(51.9)$ \\
\hline Valvular AF & $125(48.0)$ \\
\hline $\begin{array}{l}\text { Rheumatic heart disease: Mitral } \\
\text { Stenosis }\end{array}$ & $120(46.1)$ \\
\hline $\begin{array}{l}\text { Mechanical mitral valve } \\
\text { replacement }\end{array}$ & $5(1.9)$ \\
\hline Male & $114(43.8)$ \\
\hline Female & $146(56.1)$ \\
\hline Smoker & $89(34.2)$ \\
\hline Alcohol consumer & $32(12.3)$ \\
\hline \multicolumn{2}{|l|}{ Heart rate (BPM) } \\
\hline$<100$ & $151(58.0)$ \\
\hline$>100$ & 109 (41.9) \\
\hline LA/LAA clot & $30(11.53)$ \\
\hline \multicolumn{2}{|l|}{ Mean values } \\
\hline Mean BMI in kg/m² (Range) & $23.62(13.02-39)$ \\
\hline $\begin{array}{l}\text { Mean systolic blood pressure in } \\
\mathrm{mmHg} \text { (Range) }\end{array}$ & $119.60(80-180)$ \\
\hline $\begin{array}{l}\text { Mean diastolic blood pressure in } \\
\mathrm{mmHg} \text { (Range) }\end{array}$ & $77.06(50-110)$ \\
\hline Mean hemoglobin (gm/dl) (Range) & $12.38(8.3-18.7)$ \\
\hline Mean serum creatinine (mg/dl) & $0.93(0.6-1.6)$ \\
\hline Mean heart rate (BPM) & $95.65(50-160)$ \\
\hline $\begin{array}{l}\text { Mean } \mathrm{CHA}_{2} \mathrm{DS}_{2}-\text { VASc score in } \\
\text { NVAF (Range) }\end{array}$ & $1.9(0-5)$ \\
\hline
\end{tabular}

Abbreviations: BMI; body mass index, BPM; beat per minute, AF; atrial fibrillation, LA; left atrium, LAA; left atrial appendage, NVAF; non-valvular atrial fibrillation, $\mathrm{CHA}_{2} \mathrm{DS}_{2}$-VASc- Congestive heart failure, Hypertension, Age $\geq 75$ years, Diabetes mellitus, prior Stroke or transient ischemic attack, vascular disease, age 65-74, female sex

Among predisposing conditions for NVAF: left ventricular (LV) diastolic dysfunction in 87 (33.4\%), LV systolic dysfunction 84 (32.3\%), overweight or obesity 73 (28.0\%), coronary artery disease (CAD) 27 (10.3\%), hypertension with left ventricular hypertrophy (LVH) 25 (9.6\%), dilated cardiomyopathy (DCM) 17 (6.5\%), chronic obstructive airway disease (COPD) and/or cor 
pulmonale in $37(14.2 \%)$ were common (Table 2$)$.

\begin{tabular}{|ll|}
\hline $\begin{array}{l}\text { Table 2. Predisposing conditions } \\
\text { (n=260). }\end{array}$ \\
\hline Characteristics & Frequency $\mathbf{n}(\%)$ \\
Dilated LA & $231(88.8)$ \\
RHD & $125(48)$ \\
Smoking & $89(34.2)$ \\
LV diastolic dysfunction & $87(33.4)$ \\
LV systolic dysfunction & $84(32.3)$ \\
Overweight/obesity & $73(28.0)$ \\
Alcohol use & $32(12.3)$ \\
CAD & $27(10.3)$ \\
LVH & $25(9.6)$ \\
COPD & $19(7.3)$ \\
Cor pulmonale & $18(6.9)$ \\
DCM & $17(6.5)$ \\
Lone AF & $13(5)$ \\
Thyroid disorders & $3(1.1)$ \\
\hline
\end{tabular}

Abbreviations: LA; left atrium, RHD; rheumatic heart disease, LV; left ventricle, CAD; coronary artery disease, LVH; left ventricular hypertrophy, COPD; chronic obstructive pulmonary disease, DCM; dilated cardiomyopathy, AF; atrial fibrillation

Risk factors for stroke in patients with NVAF are illustrated below (Table 3).

\begin{tabular}{|ll|}
\hline $\begin{array}{l}\text { Table 3. Risk factors for stroke in non-valvular atrial } \\
\text { fibrillation }(\mathbf{n}=135) .\end{array}$ \\
\hline Risk factors for stroke & Frequency $\mathbf{n ~ ( \% )}$ \\
Age & $53(39.2)$ \\
$65-74$ years & $42(31.1)$ \\
$>75$ years & $20(14.8)$ \\
Prior stroke or TIA & $64(47.4)$ \\
CHF or LVEF <40\% & $62(45.9)$ \\
Hypertension & $14(10.3)$ \\
Diabetes Mellitus & \\
CHA2DS2VASc score & $9(6.6)$ \\
0 & $24(17.7)$ \\
1 & $41(30.3)$ \\
2 & $52(38.5)$ \\
3 & $7(5.1)$ \\
4 & $2(1.48)$ \\
5 & \\
LA size (mm) & $120(88.8)$ \\
$\leq 40 m m$ & $15(11.1)$ \\
\hline
\end{tabular}

Abbreviation: TIA; transient ischemic attack, CHF; chronic heart failure, LVEF; left ventricular ejection fraction, LA ; left atrium,CHA2DS2VASc - Congestive heart failure, Hypertension, Age $\geq 75$ years, Diabetes mellitus, prior Stroke or transient ischemic attack, vascular disease, age 65-74, female sex,

Among echocardiogram parameters, $88.8 \%$ patients had dilated LA, 135 (51.9\%) of patients had NVAF, $87(33.4 \%)$ had diastolic dysfunction, 84 (32.3\%) had systolic dysfunction, and $33 \%$ pulmonary artery hypertension. AF with fast ventricular rate 109 (41.9\%), LVH 25 (15.8\%), right ventricular hypertrophy 26 (10\%), left bundle branch block 16 (8.3\%) and right bundle branch block $8(3.3 \%)$ were the common ECG findings.

Anticoagulant prophylaxis according to each $\mathrm{CHA}_{2} \mathrm{DS}_{2}-$ VASc score is summarized below (Table 4).

\begin{tabular}{|c|c|c|c|c|}
\hline \multicolumn{5}{|c|}{$\begin{array}{l}\text { Table 4. Antithrombotic treatment in Non-valvular AF } \\
\text { according to } \mathrm{CHA}_{2} \mathrm{DS}_{2} \text {-VASc score }(\mathrm{n}=135) \text {. }\end{array}$} \\
\hline $\begin{array}{l}\mathrm{CHA}_{2} \mathrm{DS}_{2}- \\
\text { VASc score }\end{array}$ & $\begin{array}{l}\text { Frequency } \\
\mathrm{n}(\%)\end{array}$ & Aspirin & Warfarin & None \\
\hline 0 & $9(6.6)$ & 8 & 0 & 1 \\
\hline 1 & $24(17.7)$ & 18 & 0 & 6 \\
\hline 2 & $41(30.3)$ & 26 & 2 & 13 \\
\hline 3 & $52(38.5)$ & 31 & 7 & 14 \\
\hline 4 & $7(5.1)$ & 4 & 3 & 0 \\
\hline 5 & $2(1.4)$ & 0 & 1 & 1 \\
\hline
\end{tabular}

Abbreviations: $\mathrm{CHA}_{2} \mathrm{DS}_{2}-\mathrm{VASc}$ - Congestive heart failure, Hypertension, Age $\geq 75$ years, Diabetes mellitus, prior Stroke or transient ischemic attack, vascular disease, age 65-74, female sex

Among 135 patients with NVAF, 102(75.5\%) had a CHA2DS2VASC score of $\geq 2$ who were eligible for oral anticoagulants, $13(9.6 \%)$ patients received it with a majority having sub-therapeutic INR. Among 125 (48.0\%) patients with VAF, only $47(37.6 \%)$ patients were receiving oral anticoagulants and 20 (42.5\%) patients achieved therapeutic INR (Table 5). The majority of patients with VAF or NVAF were receiving Aspirin as an antithrombotic agent.

\begin{tabular}{|l}
\hline $\begin{array}{l}\text { Table 5. The number of patients with therapeutic INR } \\
\text { (between } 2 \text { and 3). }\end{array}$ \\
$\begin{array}{lll}\text { Characteristics } & \text { No. of patients } & \text { No. of patients } \\
\text { on VKA } \mathbf{n}(\%) & \begin{array}{l}\text { with therapeutic } \\
\text { INR } \mathbf{n}(\%)\end{array} \\
\text { Total } & 60(23.07) & 25(41.6) \\
\text { Valvular AF } & 47(37.6) & 20(42.5) \\
\text { Non-valvular AF } & 13(9.6) & 5(38.4)\end{array}$ \\
\hline
\end{tabular}

Abbreviations: AF; atrial fibrillation, VKA; vitamin $\mathrm{K}$ antagonist, INR; International normalized ratio

\section{DISCUSSION}

AF is the most common sustained cardiac tachyarrhythmia and a major risk factor for thromboembolism. ${ }^{7}$ Antithrombotic agents is highly effective for the reduction of thromboembolism and stroke in patients with AF. VKA is more effective than 
aspirin with a relative risk reduction of $36 \% .^{8}$

This study has shown the underuse of antithrombotic therapy in the form of either OACs or antiplatelet agents in patients with both VAF and NVAF according to contemporary international guidelines. ${ }^{9}$ About $37.6 \%$ of patients with VAF and $9.6 \%$ of patients with NVAF received OACs. The majority of patients with both VAF and NVAF were receiving Aspirin as an antithrombotic agent. Likewise, a study done in a rural part of Nepal by the same author showed that $39.1 \%$ of patients with NVAF who had a $\mathrm{CHA}_{2} \mathrm{DS}_{2}$ score of $>2$ and eligible for oral anticoagulants, only $18.9 \%$ of patients received it. Similarly, only $22.7 \%$ of patients with valvular AF obtained OACs. ${ }^{10}$

The stroke risk in patients with NVAF with a high score corresponds to greater risk while a low score corresponds to a lower risk. ${ }^{6}$ The European Society of Cardiology (ESC) ${ }^{11}$ and National Institute for Health and Care Excellence (NICE) ${ }^{12}$ guidelines recommend that if the patient has a CHA2DS2-VASc score of two and above, OAC is recommended. In our study, among 135 patients with non-valvular AF, 75.5\% had a CHA2DS2VASc score of $\geq 2$ who were eligible for oral anticoagulants, only $9.6 \%$ of patients received it with the majority having sub-therapeutic INR.

Most of the discussions about the risk of stroke are related to NVAF from the western world. Owing to the high burden of RHD in our part of the world, we have a good number of mitral stenosis (MS) which increases the risk of stroke even in absence of AF, and the risk is increased markedly in the presence of AF. The risk of stroke is increased 17 fold in patients with AF and RHD. ${ }^{13}$ In our study, $48.0 \%$ of total patients with AF had RHD with MS and $37.6 \%$ of these patients were on OACs. Only $42.5 \%$ of patients who were receiving OACs attained therapeutic INR. This indicates the inadequate use of this highly effective anticoagulant therapy among patients with VAF who are at high risk for stroke.

Some of the patient factors related to OAC underuse could be a lack of awareness or need for monthly INR monitoring with the use of VKA. The reasons for under-treatment seem complex but may include lack of knowledge about trials or guidelines among treating physicians, bleeding risk, poor drug compliance, cost of treatment, inconvenience of INR monitoring, unavailability and high cost of newer direct oral anticoagulants (DOACs). Continuing efforts should be made to improve patients' awareness and understanding of the disease process as well as the need for OAC therapy. ${ }^{14}$

Education to health personnel and patients on stroke prevention from AF may improve the prescription rate of antithrombotic therapy. The stroke risk stratification scheme may help to determine which drug is most appropriate for different risk category patients. To facilitate the tailored treatment, guideline formulation group and physicians should focus on providing uniform and easy to use risk stratification tool. Patient's knowledge about antithrombotic therapy for AF might be improved by an information booklet. ${ }^{15}$ There is still an unmet need for safer and easier to use antithrombotic drugs in Nepal.

This is a small cross-sectional study representing patients from the eastern part of Nepal. The therapeutic INR values may not be appropriate for comparison with other studies because a single INR value was noted at the time of enrollment. We found the marked underuse of antithrombotic in patients with AF but we did not look at the physician's and patient's factors for not prescribing antithrombotic treatment. Bleeding risk scores were not taken into account. Since DOACs are not easily available or costly in our country so data on the use of DOACs is not presented in this study.

\section{CONCLUSIONS}

This study provides information about current practices of the use of antithrombotic agents and stroke risk in our patient's population with AF. OACs were markedly underused who qualified for it. This indicates the need for appropriate use of OACs to prevent thromboembolism and stroke. Improved awareness and understanding of the perceived risks of underutilization of antithrombotics among physicians and patients may improve its use. Specialized anticoagulation clinics and laboratory services at the grassroot health care center may help to initiate and maintain safe oral anticoagulant therapy.

\section{ACKNOWLEDGEMENTS}

We would like to express our sincere thanks to junior residents of Internal Medicine, Nobel Medical College Teaching Hospital for their support to collect data of study participants.

\section{Conflict of interest: None.}

\section{REFERENCES}

1. Go AS, Hylek EM, Phillips KA, Chang Y, Henault LE, Singer DE. Prevalence of diagnosed atrial fibrillation in adults: national implications for rhythm management and stroke prevention: the Anticoagulation and Risk Factors in Atrial Fibrillation (ATRIA) Study. JAMA. 2001;285:2370-5. [PubMed | DOI]

2. Go AS, Hylek EM, Chang Y, Phillips LA, Henault LE, Capra 
AM, et al. Anticoagulation therapy for stroke prevention in atrial fibrillation: how well do randomized trials translate

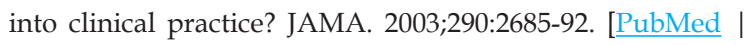
DOI]

3. The Clinical Quality Improvement Network (CQIN) Investigators. Thromboembolic prophylaxis in 3575 hospitalized patients with atrial fibrillation. Can J Cardiol. 1998;14:695-702. [PubMed]

4. Albers GW, Yim JM, Belew KM, Bittar N, Hattemer CR, Phillips BG, et al. Status of antithrombotic therapy for patients with atrial fibrillation in university hospitals. Arch Intern Med. 1996;156:2311-6. [라Med | Full Text ]

5. Lip GY, Nieuwlaat R, Pisters R, Lane DA, Crijns HJGM. Refining clinical risk stratification for predicting stroke and thromboembolism in atrial fibrillation using a novel risk factor-based approach: the euro heart survey on atrial fibrillation. Chest. 2010;137:263-72. [PubMed | Full Text $\mid \underline{\text { DOI] }}$

6. Adhikari K, Malla R, Limbu D, Rauniyar B, Regmi S, Hirachan A, et al. Prevalence of Atrial Fibrillation in patients attending emergency department of Shahid Gangalal National Heart Centre, Kathmandu, Nepal. Nepalese Heart Journal, 2016;13(1):1-4. [Full Text | DOI]

7. Wolf PA, Abbott RD, Kannel WB. Atrial fibrillation as an independent risk factor for stroke: the Framingham Study. Stroke. 1991;22:983-8. [ㅁubMed | Full Text | DOI]

8. Hart RG, Benavente O, McBride R, Pearce LA. Antithrombotic therapy to prevent stroke in patients with atrial fibrillation: a meta-analysis. Ann Intern Med. 1999 Oct 5;131(7):492-501. [PubMed | DOI]
9. Atrial Fibrillation Investigators 1994. Risk factors for stroke and efficacy of antithrombotic therapy in atrial fibrillation: analysis of pooled data from five randomized controlled trials. Am Intern Med. 1994 Jul 11;154:1449-57. [PubMed | $\underline{\mathrm{DOI}}$

10. Dhungana SP, Sherpa K. Antithrombotic agents and Risk Profile of Patients with Atrial Fibrillation from Rural Part of Nepal. JIOM. 2015 Aug; 37(2):16-21. [Full Text]

11. ESC Guidelines for the management of atrial fibrillation developed in collaboration with EACTS. European Heart Journal. 2016 Oct 7;37(38):2893-2962. [PubMed | Full Text [ DOI]

12. Atrial fibrillation: Management. NICE Guidelines. Clinical guideline Published: 18 June 2014. [Full Text]

13. Caterina R, Camm AJ. What is "valvular" atrial fibrillation? A reappraisal. Eur Heart J. 2014 Dec 14;35:3328-35. [Full Text | DOI]

14. Lip GY, Kamath S, Jafri M, Mohammed A, Bareford D. Ethnic differences in patient perceptions of atrial fibrillation and anticoagulation therapy: the West Birmingham Atrial Fibrillation Project. Stroke. 2002 Jan;33:238-42. [PubMed | DOI]

15. Lane DA, Ponsford J, Shelley A, Sirpal A, Lip GY. Patient knowledge and perceptions of atrial fibrillation and anticoagulant therapy: Effects of an educational intervention programme The West Birmingham Atrial Fibrillation Project. Int J Cardiol. 2006 Jun 28;110(3):354-358. [PubMed | DOI]

(C) The Author(s) 2018.

This work is licensed under a Creative Commons Attribution 4.0 International License. The images or other third party material in this article are included in the article's Creative Commons license, unless indicated otherwise in the credit line; if the material is not included under the Creative Commons license, users will need to obtain permission from the license holder to reproduce the material. To view a copy of this license, visit http://creativecommons.org/licenses/by/4.0/ 